\title{
CURRÍCULO BASEADO EM COMPETÊNCIAS NA FORMAÇÃO CONTINUADA DE PROFESSORES DA EDUCAÇÃO PROFISSIONAL E TECNOLÓGICA: CONTRIBUIÇÕES DE PROGRAMAS FINLANDESES
}

\author{
CURRÍCULO BASADO EN COMPETENCIAS EN LA FORMACIÓN \\ CONTINUADA DE PROFESORES DE LA EDUCACIÓN PROFESIONAL Y \\ TECNOLÓGICA: CONTRIBUCIONES DE PROGRAMAS FINLANDESES
}

COMPETENCE-BASED CURRICULUM IN THE IN-SERVICE TEACHER VOCATIONAL EDUCATION: CONTRIBUTIONS FROM FINNISH PROGRAMS

\author{
Azenaide Abreu Soares VIEIRA ${ }^{1}$ \\ Sheylla CHEDIAK ${ }^{2}$
}

RESUMO: Esse artigo visa apresentar a estrutura curricular do Programa Finlandês de Formação continuada de professores formadores brasileiros - FiTT Finnish Training the Trainers, bem como o curso RE-MAES: Rede de Formadores em Metodologias de Aprendizagem Ativa centradas no estudante do século XXI, guiado pelos mesmos princípios. Além de discorrer sobre os dois programas, objetiva-se investigar de que forma o RE-MAES, desenhado e desenvolvido por educadores brasileiros à luz da aprendizagem construída junto aos educadores finlandeses, aproxima-se ou distancia-se do FiTT para atender a realidade local. A pesquisa pode contribuir para a construção do "jeito" brasileiro de formar professores e é relevante por ir ao encontro da necessidade em se repensar e reconstruir cursos de formação continuada de professores no Brasil de forma a alinhá-los ao paradigma emergente da aprendizagem ativa. Trata de uma pesquisa qualitativa, descritiva e explicativa. Os dados emergiram dos projetos pedagógicos dos programas, materiais construídos pelos formadores e notas de campos das pesquisadoras, participantes ativas como formadas pelo FiTT e formadoras do REMAES. O estudo traz como base teórica os princípios da educação finlandesa que preconiza o alinhamento de métodos de ensino e avaliação aos objetivos de aprendizagem, norteados pelos princípios da educação baseada em competências e pelo paradigma da aprendizagem ativa, centrada no estudante. O estudo revela que na dinâmica de pensar sobre a experiência vivida e nas formas de multiplicação, a realidade do contexto é decisiva no desenho do curso, constituindo um modelo ressignificado de formação continuada de professores que atenda peculiaridade dos participantes.

${ }^{1}$ Instituto Federal de Educação, Ciência e Tecnologia do Mato Grosso do Sul (IFMS), Nova Andradina -MS - Brasil. Professora EBTT. Pós-doutorado. Doutora em Estudos Linguísticos/UNESP. Participante do Programa VET III - Teachers for the Future/2016 e do Programa FiTT - Finnish Training the Trainers /2017. ORCID: <https://orcid.org/0000-00034175-6317>. E-mail: azenaide.vieira@ifms.edu.br

${ }^{2}$ Instituto Federal de Educação, Ciência e Tecnologia de Rondônia (IFRO), Porto Velho - RO Brasil. Professora EBTT. Doutoranda em Educação (UNESP). Mestre em Psicologia Escolar. Participante do Programa VET II - Teachers for the Future/2015 e do Programa FiTT - Finnish Training the Trainers/2017. ORCID: <http://orcid.org/0000-0002-0624-2516>. E-mail: sheylla.chediak@ifro.edu.br 
PALAVRAS CHAVE: Ensino por competências. Formação continuada de professores. Currículo.

RESÚMEN: Este artículo tiene como objetivo presentar la estructura curricular del Programa Finlandés de Formación continuada de profesores formadores brasileños "FiTT Finnish Training the Trainers", bien como como el curso RE-MAES: Red de Formadores en Metodologías de Aprendizaje Activo centradas en el estudiante del Siglo XXI, guiado por los mismos principios. Además de discurrir sobre los dos programas, se pretende investigar de qué forma el RE-MAES, diseñado y desarrollado por educadores brasileños a la luz del aprendizaje construido junto a los educadores finlandeses, se aproxima o se aleja del FiTT para atender la realidad local. La investigación puede contribuir a la construcción del "estilo" brasileño de formar profesores y es relevante porque va al encuentro de la necesidad de repensar y reconstruir cursos de formación continuada de profesores en Brasil para alinearlos al paradigma emergente del aprendizaje activo. Se trata de una investigación cualitativa, descriptiva y explicativa. Los datos surgieron de los proyectos pedagógicos de los programas, materiales construidos por los formadores y notas de campos de las investigadoras, participantes activas del FiTT, formadas por él y formadoras del RE$M A E S$. El estudio trae como base teórica los principios de la educación finlandesa que preconiza el estrechamiento de métodos de enseñanza y evaluación a los objetivos de aprendizaje, orientados por los principios de la educación basada en competencias y por el paradigma del aprendizaje activo centrado en el estudiante. El estudio revela que en la dinámica de pensar sobre la experiencia vivida y en las formas de multiplicación, la realidad del contexto es decisiva en el diseño del curso, constituyendo un modelo resignificado de formación continuada de profesores que atienda la peculiaridad de los participantes.

PALABRAS CLAVE: Formación de profesores. Educación por competencias. Plan de estudios.

ABSTRACT: This paper aims at presenting the curricular structure of the Finnish Continuing Education Program for Brazilian trainers, named "FiTT - Finnish Training the Trainers" as well as a course created on the same basis, entitled RE-MAES: Network of Trainers of Active Learning Methodologies centered on the 21st Century student. In addition to discussing the programs, the objective is to investigate how REMAES course, designed and developed by Brazilian educators and based on the knowledge constructed throughout FiTT course in Finland, approaches or distances from FiTT program to meet local reality. This research may contribute to the creation of the Brazilian "way" to provide teacher continuing education, which is relevant since there is a need to rethink and reconstruct teacher development courses in Brazil in order to align them with the emerging paradigm of active learning. This research is characterized as qualitative, descriptive and explanatory. Data have emerged from the pedagogical projects of the programs, materials built by the trainers and the researchers' observations, who have been performing as active participants, certified by the FiTT program and accredited as RE-MAES trainers. The study theoretical framework considers some Finnish education cornerstones, which advocate the alignment of teaching and assessment methods with learning objectives, based on competence-based education concepts, as well as student-centered and active learning

RPGE - Revista on line de Política e Gestão Educacional, Araraquara, v. 22, n. 2, p. 554-571, maio/ago., 2018. ISSN: 1519-9029. DOI: 10.22633/rpge.v22.n2.maio/ago.2018.11429 
paradigms. The study shows that in the dynamics of thinking about the experience and knowledge distribution strategies, the context reality is decisive in the course design, constituting a resignified model of teacher education that responds to the participants' peculiarity.

KEYWORDS: Competence-based education. In-service teacher education. Curriculum.

\section{Para começar}

Muito tem se discutido sobre os excelentes resultados apresentados pelos estudantes finlandeses em exames internacionais, a exemplo no Programa Internacional de Avaliação de Estudantes PISA (Programme for International Student Assessment), que visa contribuir para a discussão sobre a qualidade da educação nos países participantes e, assim, subsidiar na construção de políticas de melhoria do ensino na Educação básica. Como consequência disso e diante do reconhecimento da qualidade da educação pública ofertada na Finlândia, desde 2013 o Brasil, representado pela Secretaria de Educação Profissional e Tecnológica - SETEC/MEC conta com a parceria desse país para formar Professores da Rede Federal de Educação Profissional, Científica e Tecnológica, mediante dois Programas, sendo pelo VET (Vocational Education and Training) Teachers for the Future e FiTT Finnish Training the Trainers.

Com a parceria entre a Secretaria de Educação Profissional e Tecnológica do Ministério da Educação (SETEC/MEC) e duas (2) universidades de Ciências Aplicadas na Finlândia - Häme University of Applied Sciences (HAMK) e Tampere University of Applied Sciences (TAMK) -, em 2017 o Brasil totalizou cento e sete (107) Professores da Educação Profissional de diferentes regiões do país formados pelo Programa VET Professores para o Futuro. Foram três (3) grupos de professores brasileiros formados, sendo vinte e sete (27) professores pelo VET I (2014), trinta e quatro (34) professores pelo VET II (2015) e quarenta e seis (46) professores pelo VET III (2016).

Nessa direção, em 2017 mais um passo foi dado no âmbito da parceria entre os dois governos. As instituições finlandesas HAMK e TAMK selecionaram vinte (20) professores na missão de multiplicar os conhecimentos adquiridos pelo VET e os convidaram para voltar à Finlândia para um (1) mês de formação pelo Programa FiTT Finnish Training the Trainers (Agosto/2017).

O objetivo do Programa VET é formar professores para multiplicar práticas exitosas de ensino e aprendizagem na Educação Profissional Brasileira em diferentes 
regiões do Brasil. Já, o Programa FiTT visa formar formadores para multiplicar os conhecimentos construídos com os Educadores Finlandeses em programas de formação de professores.

Diante das responsabilidades assumidas com a participação nos Programas Finlandeses de formação de professores, construímos inúmeras atividades de ensino, pesquisa e extensão à luz do paradigma educacional finlandês e ancorados na realidade local. Dentre as atividades de extensão, destaca-se o Programa MAES: Metodologias Ativas de Aprendizagem para o Estudante do Século XXI e, a partir deste, o RE-MAES: Rede de Formadores em Metodologias de Aprendizagem Ativa para o Estudante do Século XXI, tendo em vista que buscam atender dois problemas apontados por Abrucio (2016) nos cursos de formação de professores no Brasil, sendo a falta de abordagem didática e a necessidade de mudanças nos currículos dos cursos de formação de professores.

Temos ciência de nossa responsabilidade como educador-formador-pesquisador contemplados com programas de formação pedagógica internacional, incentivados pelo governo federal, sendo assim, a partir de um ângulo privilegiado e do olhar atento ao fazer do outro, analisamos como o Programa brasileiro de Formação Docente REMAES apropria-se e ressignifica o Programa de formação de professores desenvolvido pelos educadores finlandeses da TAMK e da HAMK School of Professional Teacher Education, em Tampere e Hämeenlinna/Finlândia. A expectativa é de que o presente texto contribua para construção de modelos de formação de professores em diferentes cenários da Educação Profissional no Brasil.

\section{Efeito Caleidoscópio do Programa FiTT}

A imaginação é a faculdade de formar imagens que ultrapassam a realidade, que cantam a realidade. A imaginação inventa mais que coisas e dramas, inventa vida nova.

Gaston Bachelard

Um caleidoscópio (ou calidoscópio) é um tubo que a partir de combinações de pedaços de vidro colorido inclinado apresentam em seu interior efeitos visuais variados conforme movimentos e reflexo da luz do ambiente. Somado ao movimento da mão e ao reflexo da luz exterior, o efeito visual provocado pelo caleidoscópio também é fruto 
da imaginação do observador, que inventa imagens e constrói novos significados para o que é observado.

A apresentação do Programa FiTT é compreendida como se estivéssemos observando um caleidoscópio, com efeitos criados pela luz, movimento e significados peculiares de nossa imaginação, sem descartar os efeitos produzidos e os novos significados que poderão ser construídos pelos demais professores e formadores que participaram do mesmo Programa.

\section{O fundamento do FiTT}

O FiTT teve como fundamento o currículo baseado em competência na formação continuada de professores da Educação Profissional e Tecnológica e seu escopo foi a elaboração do próprio currículo para a formação continuada de outros professores. O trabalho de elaboração do currículo compôs a sequência didática, considerando aspectos como o desenho do programa, o delineamento das competências, bem como os objetivos de aprendizagem e as formas de avaliação formativa, a implementação (prevendo recursos, materiais e métodos) e, por fim, a avaliação dos resultados alcançados. A construção do projeto deu-se a partir da abordagem de Aprendizagem Baseada em Projetos e os participantes aprenderam a elaborar o currículo na prática, desenvolvendo habilidades a partir dessa construção.

O projeto, elaborado ao longo de quatro semanas por 20 participantes, não foi considerado um produto acabado, mas como ponto de partida para nortear a elaboração de projetos semelhantes, de acordo com o contexto regional e o público-alvo. Dentre os principais aspectos do programa estavam a aprendizagem prática, flexibilidade, a colaboração, o dinamismo, a autenticidade e a integração. $O$ princípio da transdisciplinaridade foi aplicado, a avaliação formativa adotada como norteadora de todo o processo, assim como a metodologia ativa. Todos os elementos compunham a natureza do programa, cujo objetivo central está no desenvolvimento de competências.

As abordagens baseadas em competências na educação não são novas, conforme argumentam Struyven e Meyst.

Embora o conceito de "competências" tenha aparecido pela primeira vez em 1890, surgiu um interesse crescente na formação e treinamento baseados em competências nas décadas de 1960 e 1970, como resultado de várias publicações sobre treinamento organizacional baseado em competências e formação de professores baseada em 
competências $\left(\mathrm{CBTE}^{3}\right)$ [...]. (STRUYVEN; MEYST, 2010, p. 1495). [Tradução nossa].

Segundo essas autoras, a demanda por uma educação mais voltada para o "saber fazer" surge, principalmente, no período após a segunda guerra mundial, quando o gerencialismo e as características inerentes a ele, tais como eficiência, eficácia e responsabilidade na prestação de contas, torna-se necessário nas instituições.

O conceito de instrução baseada em competências emergiu da ênfase na orientação de acordo com o objetivo e na individualização. Os objetivos de aprendizagem são definidos em termos comportamentais e avaliáveis e podem ser explicitados, por e para o aluno. O indivíduo então pode buscar atividades de aprendizagem e pode desenvolver habilidades de desempenho ou competências no processo. Dentro da lógica do movimento CBTE [formação de professores baseada em competência], "competência" indica uma ênfase na "capacidade de fazer", e é considerado sinônimo de habilidades de desempenho. (STRUYVEN; MEYST, 2010, p. 1496). [Tradução nossa].

A importância do aprender a fazer é defendida, sem a diminuição da relevância do conhecimento, compreendido por nós como o conteúdo. A união desses sobrepõe-se ao saber desconexo da realidade e da prática social. Neste sentido, Koenen, Dochy e Berghmans (2015) explicam que o currículo baseado em competências no Ensino Superior surgiu como uma demanda em busca da superação do distanciamento criado entre a teoria e a prática - "A ideia de competências foi introduzida no ensino superior por causa da desconexão entre o que era ensinado nas aulas e o que era necessário no mercado de trabalho (p. 1) [Tradução nossa].". Sendo assim, essa necessidade estava ligada com o ensinar a aplicabilidade do conhecimento teórico, rejeitando o acúmulo deste sem uma aplicação prática.

A declaração de Bolonha de 1999 foi assinada por 29 países da Europa que se comprometeram a melhorar a competitividade do ensino superior europeu, tornando-o "[...] capaz de fornecer aos cidadãos as competências necessárias para encarar os desafios do novo milênio (THE EUROPEAN HIGHER EDUCATION AREA, 1999)." [Tradução nossa]. A Finlândia aderiu-se à União Europeia em $1995^{4}$ e também comprometeu-se, a partir da declaração de Bolonha, a promover uma educação voltada para o desenvolvimento de competências que atendessem ao século XXI.

${ }^{3}$ CBTE - Competence-Based Teacher Education: traduzido como Formação de Professores baseada em competências.

${ }^{4}$ Fonte: <https://europa.eu/european-union/about-eu/countries/member-countries/finland_pt> RPGE - Revista on line de Política e Gestão Educacional, Araraquara, v. 22, n. 2, p. 554-571, maio/ago., 2018. ISSN: 1519-9029. DOI: 10.22633/rpge.v22.n2.maio/ago.2018.11429 
O termo competência ganha destaque no final do século $\mathrm{XX}$ e se fortalece no século XXI não só no ensino superior, mas também nos demais níveis e modalidades da Educação. Como exemplo, o relatório para UNESCO da Comissão Internacional sobre Educação para o século XXI, coordenado por Delors (1996) que estabeleceu os quatro pilares da educação: aprender a ser, a conviver, a conhecer e a fazer, esse último remetendo também à aplicabilidade do conhecimento na prática.

A demanda por um ensino que considere a aprendizagem de competências tornou-se uma tendência global, dados os fenômenos da globalização e internacionalização e a consequente determinação de organismos financeiros internacionais dos quais muitos países, incluindo o Brasil, aderem. Neste sentido, Kempner e Jurema (2002) criticam e explicam que a determinação de organismos financeiros, como o Banco Mundial, para países como o Brasil ou outros em desenvolvimento, se dá por associação, que impõe solução global para problemas de contextos específicos.

Enquanto as teorias da modernização assumem que todos os países desejam ser modernos nas mesmas concepções ocidentais de desenvolvimento, as teorias neoliberais subjacentes à globalização consideram, também, que todos os países irão se beneficiar igualmente da dependência do mercado. Semelhante à teoria da modernização, o discurso da globalização é apresentado pelos seus defensores neoliberais como neutros, objetivos e em todos os interesses das nações, independentemente das suas circunstâncias políticas e econômicas e nível de desenvolvimento (KEMPNER e JUREMA, 2002, p. 331-332) [Tradução nossa].

Desta forma, tomadas pela internacionalização das ações em várias esferas sociais de países ocidentais e inspiradas em teorias que sustentam a organização econômica das sociedades capitalistas, o ensino por competências se coloca como preponderante diante das demandas para o século XXI. Não defendemos a neutralidade das propostas do ensino baseado em competências, mas defendemos a busca pela superação através de um ensino que não despreze, em hipótese alguma, o conhecimento, entendido aqui como conteúdo como sustentação (alicerce) do aprender a fazer.

\section{O percurso didático-pedagógico construído pelos Formadores}

O FiTT foi desenvolvido na Finlândia ao longo de quatro semanas, com carga horária total de 120 horas. Nas semanas antecedentes às aulas presenciais, os professores receberam atividades online para levantamento do perfil dos participantes e 
para autoavaliação. O grupo foi constituído de vinte professores de diferentes áreas do conhecimento, servidores dos Institutos Federais de Educação, Ciência e Tecnologias.

As semanas foram organizadas em temas que sugeriram a orientação das ações e podem ser resumidas no Quadro 1.

Quadro 1: Organização temática do curso

\begin{tabular}{|l|l|}
\hline $\begin{array}{l}\text { Semanas } \\
\text { antecedentes } \\
\text { às aulas } \\
\text { presenciais }\end{array}$ & $\begin{array}{l}\text { Avaliação diagnóstica e construção da comunidade de aprendizagem. } \\
\text { Autoavaliação das competências. }\end{array}$ \\
\hline Semana 1 & $\begin{array}{l}\text { Design do programa, garantia de qualidade e formas de entrega } \\
\text { Introdução geral ao programa. Levantamento de expectativas/necessidades } \\
\text { para construção do currículo de Formação continuada para Educação } \\
\text { Profissional e Tecnológica. }\end{array}$ \\
\hline Semana 2 & $\begin{array}{l}\text { Alinhamento construtivo e design educacional } \\
\text { Criação do currículo para o curso de formação continuada para EPT no } \\
\text { Brasil - alinhamento das competências e objetivos de aprendizagem. } \\
\text { Planejamento da avaliação. Habilidades de Comunicação. }\end{array}$ \\
\hline Semana 3 & $\begin{array}{l}\text { Planejamento da implementação } \\
\text { Exploração de diferentes ferramentas digitais necessárias para o processo e } \\
\text { foco nos métodos de aprendizagem necessários para integração do } \\
\text { professor e desenvolvimento educacional. Avaliação de habilidades de } \\
\text { auto liderança. }\end{array}$ \\
\hline $\begin{array}{l}\text { Resultados Finais } \\
\text { Finalização coletiva dos planos de implementação e compartilhamento das } \\
\text { orientações para o trabalho colaborativo do curso de Formação continuada } \\
\text { para Educação Profissional. } \\
\text { Autoavaliação individual e análise dos resultados alcançados. }\end{array}$ \\
\hline
\end{tabular}

Fonte: Os autores

As duas primeiras semanas de aulas presenciais foram realizadas na Universidade de Ciências Aplicadas TAMK, na cidade de Tampere, e as duas últimas em HAMK, em Hämeenlinna. Não podemos deixar de mencionar a peculiaridade do programa que se deu em um processo de imersão cultural, em situação de mobilidade.

Já no acordo entre as universidades finlandesas e a SETEC/MEC, as competências que deveriam ser desenvolvidas no grupo de participantes foram previamente definidas e adotadas como o núcleo da formação do FiTT, sendo elas:

a. Habilidades de comunicação avançadas em contextos profissionais e organizações educacionais; 
b. Planejamento e desenvolvimento de currículo baseado em competências no contexto da formação de multiplicadores (inclui garantia contínua de qualidade e a habilidade de treinar professores e estudantes adultos com a abordagem centrada no estudante);

c. Planejamento da implementação, treinamento de professores e produção de material de ensino no contexto do treinamento de professores;

d. Habilidades para cooperar e criar redes de trabalho sólidas de professores especializados na formação de multiplicadores;

e. Habilidades para antecipar tendências futuras na educação e no mundo do trabalho 5 .

Tais competências também constituíram a base do currículo que os participantes tiveram que construir para multiplicar os saberes. Desta forma, podemos concluir que o FiTT se deu em um metaprocesso, ou seja, o processo de construção do currículo definiu o próprio processo. No constante exercício reflexivo, os participantes foram colocados diante de desafios de autorregulação, de pensamento crítico sobre suas próprias competências e de percepção de seus processos cognitivos. Assim sendo, ao construírem um currículo baseado em competências para formação continuada de professores da EPT, que visava o desenvolvimento de habilidades como a colaboração, a comunicação, a liderança e a criatividade, os participantes tiveram que pensar, avaliar e desenvolver em si mesmo tais habilidades.

\section{A espinha dorsal do Programa RE-MAES}

A partir da experiência adquirida como cursistas no Programa VET e FiTT somada aos conhecimentos construídos ao planejar e desenvolver o Programa MAES, estruturamos o Programa RE-MAES: Rede de Formadores em Metodologias de Aprendizagem ativa para o Estudante do Século XXI, implementado de fevereiro a novembro de 2018 no Instituto Federal de Educação Profissional, Científica e Tecnológica de Mato Grosso do Sul (IFMS), campus Nova Andradina.

Os fundamentos teórico-metodológicos adotados para construção do currículo do Programa de formação de professores-formadores RE-MAES encontram respaldo, principalmente, nos princípios da aprendizagem baseada em projeto e da educação por competência, na tentativa de aproximar aos mesmos percursos teóricos do FiTT.

Quanto à metodologia, alguns ajustes foram necessários para atender à realidade local. Por atender profissionais em exercício, a carga horária 120 horas foram

\footnotetext{
${ }^{5}$ Plano de Trabalho do FiTT apresentado pela SETEC/MEC e enviado para o e-mail dos participantes.
} 
distribuídas em nove 9 meses de estudo, respeitando a carga horária máxima de cinco 5 horas semanais de interação entre formadores e cursistas em múltiplos ambientes de aprendizagem, ora presencial ora virtual.

Assim como o FiTT, objetivamos promover um espaço de aprendizagem colaborativa para construção de um currículo de formação de professores baseado em competências, em uma dinâmica ativa de refletir sobre as competências necessárias ao outro a partir do desenvolvimento de suas próprias competências. Como ponto de partida, ressignificamos e traçamos as competências gerais a serem desenvolvidas no RE-MAES a partir de nossas próprias necessidades:

a) planejar um currículo de Formação de Professores baseado em competências, conforme necessidades locais;

b) produzir material didático e planejar ações para promover formação de professores;

c) produzir conhecimento científico à luz de problemas reais da escola;

d) promover a melhoria da comunicação no contexto do mundo do trabalho e nas organizações educacionais;

e) reconhecer as tendências educacionais e no mundo do trabalho.

O Programa RE-MAES foi desenhado em duas (2) fases complementares, no entanto independentes. A primeira fase, buscamos seguir o mesmo delineamento do FiTT, iniciando com avaliação diagnóstica e construção da comunidade de aprendizagem, seguido pela construção do desenho (design) do programa, do alinhamento construtivo entre objetivos de aprendizagem, metodologia, avaliação e ambientes de aprendizagem, do planejamento da implementação do programa, e incidindo na apresentação dos resultados "finais" considerado o tempo de término da etapa de estudo.

O núcleo central do RE-MAES consiste no planejamento de um currículo baseado em competências, com a adoção da metodologia de aprendizagem baseada em projeto, conforme figura 1:

Figura 1: Núcleo central do RE-MAES 


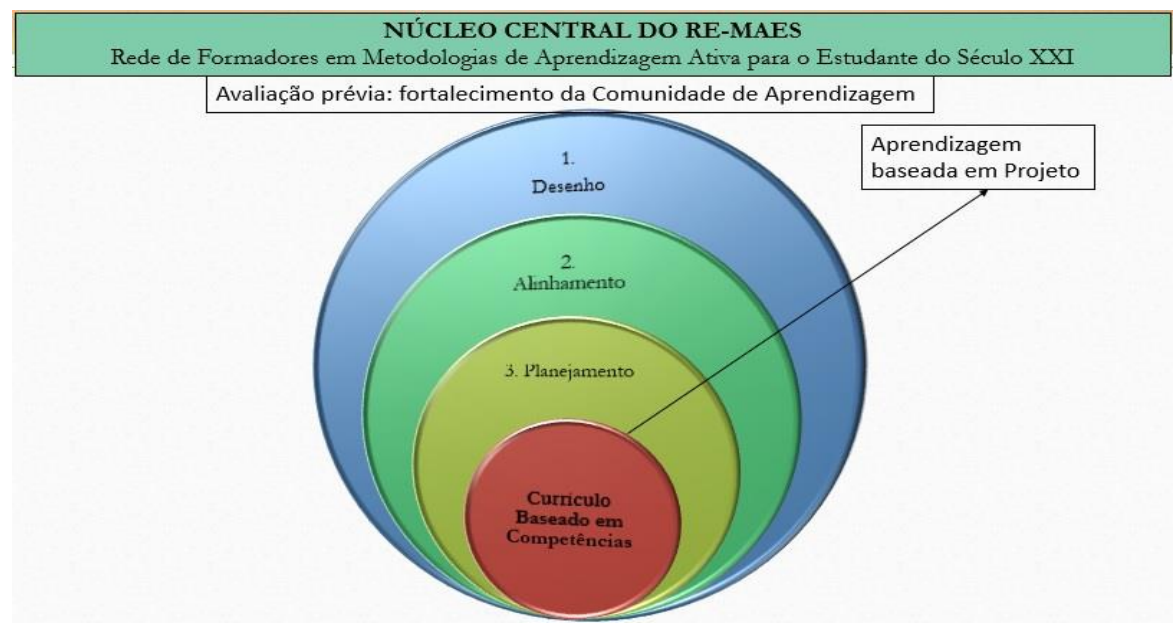

Fonte: Os autores

Ao término da fase 1, os cursistas poderão optar por encerrar o curso ou dar continuidade com a efetivação da fase 2 do RE-MAES. Na segunda fase, os cursistas realizarão visitas em escolas escolhidas por eles, consideradas "inovadoras" por apresentarem, principalmente, organizações curriculares que se aproximam do currículo construído, produto da primeira fase do curso. Concomitantemente, serão construídos textos científicos a fim de disseminar os conhecimentos fomentados na primeira fase.

Na figura 2 trazemos a estrutura curricular do RE-MAES com as duas fases propostas pelos formadores:

Figura 2: Fases do Programa RE-MAES

FASE 2 - Agosto a novembro de 2018

FASE 1 - Fevereiro a Junho de 2018
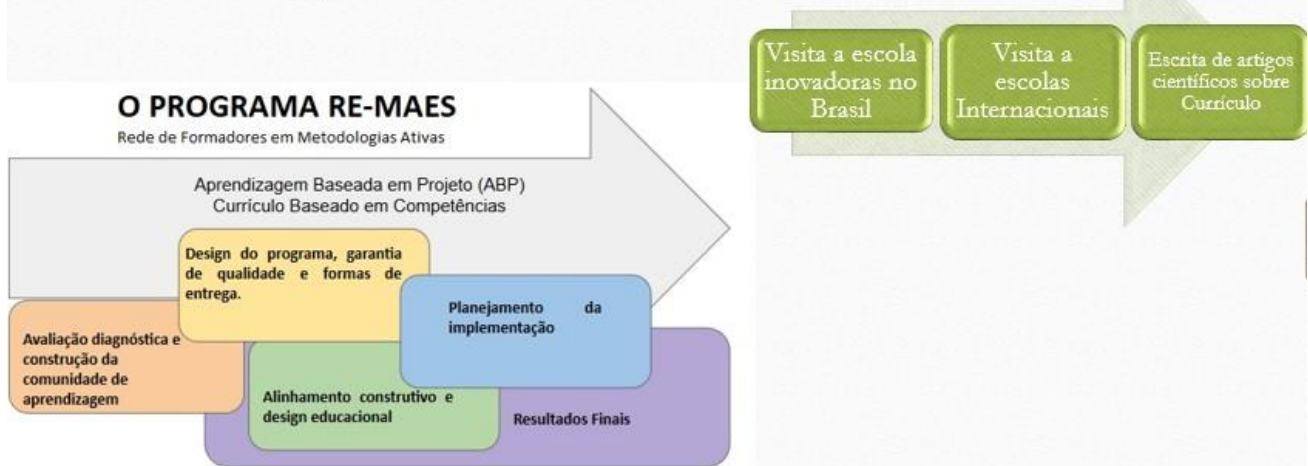

Fonte: Os autores

Levando em consideração que os cursistas matriculados no RE-MAES são professores com uma carga horária de quarenta 40 horas semanais de trabalho em Secretarias de Educação ou em Escolas de Educação Básica, além de acumularem uma 
elevada carga diária de trabalho, o curso é ofertado no noturno, com no máximo três horas presenciais e duas horas de atividades online, orientadas, gerenciadas e realizadas no google drive.

$\mathrm{Na}$ tentativa de superar a rigidez do currículo no que concerne à carga horária de efetivação dos estudos, aos cursistas é proposto a individualização da aprendizagem na constituição da carga horária do curso e no desenvolvimento de habilidades. Isso significa que eles não serão prejudicados caso não consigam comparecer a todos encontros presenciais com os formadores ou caso não realizem todas as atividades online. Sua certificação se dará pela carga horária efetivada e habilidades demonstradas ao longo de seu percurso formativo. Para que isso seja possível, cada formador local atuará como mentor de até oito (8) cursistas, se responsabilizando pela orientação individualizada de seu mentorados.

A mentoria na formação continuada do professor relaciona-se com os conceitos de Schon (1987) sobre a epistemologia da prática reflexiva, ou seja, o conhecimento escolar e a capacidade do professor refletir na ação. Ele sugere que a pequenos grupos podem criar um novo tipo de pesquisa colaborativa, mais "utilizável", com aplicabilidade na prática, destinada a "[...] a curar as divisões entre o ensino e o fazer, escola e vida, pesquisa e prática, que tem sido tão sutilmente eficazes para amortecer a experiência escolar em todos os níveis (SCHON, 1987)"’6.

A mentoria geralmente se dá de forma que os professores mais experientes atuam como mentores dos iniciantes (REALI et al, 2008). Esse modelo entende que o trabalho educativo é processual e que a escola fornece não somente dados para pesquisa, mas também atividade de pesquisa, ou seja, concebe que “[...] as partes envolvidas assumem papéis de natureza colaborativa, diferentes sim, mas em que cada um tem o que aprender com o outro e em que a relação estabelecida entre os professores da escola e os da universidade é multifacetada e não hierarquizada (REALI et.al., 2008, p. 80). " Dessa maneira, o papel do formador passa a ser de criar ambientes de interação entre os aprendizes mediante recursos tecnológicos e metodologias de aprendizagem ativa, a fim de promover um efetivo trabalho de mediação pedagógica, entendido por Masetto como:

${ }^{6}$ Apresentação proferida no Encontro da Associação de Pesquisa Educacional Americana, em 1987, cujo título foi "Formando o professor reflexivo". Texto transcrito por Jan Carrick, jan/1998 e postado por Tom Russell, Queen's University, jan/1998. Disponível em <http://resources.educ.queensu.ca/ar/schon87.htm>. Acesso em: 10 jan. 2018.

RPGE - Revista on line de Política e Gestão Educacional, Araraquara, v. 22, n. 2, p. 554-571, maio/ago., 2018. ISSN: 1519-9029. DOI: $10.22633 /$ rpge.v22.n2.maio/ago.2018.11429 
[...] a atitude, o comportamento do professor (formador) que se coloca como um facilitador, incentivador ou motivador da aprendizagem, que se apresenta com a disposição de ser uma ponte entre o aprendiz e sua aprendizagem - não uma ponte estática, mas uma ponte "rolante", que ativamente colabora para que o aprendiz chegue aos seus objetivos. (MASETTO, 2000, p. 144-145)

Percebe-se que a mediação, respalda-se nos preceitos da aprendizagem colaborativa, caracterizada a partir da relação dialógica que se estabelece entre os participantes, na busca de resolução de problemas. No caso do RE-MAES a mediação acontece a partir da mentoria por pares organizados em grupos - Peer-Group Mentoring (TYNJÄLÄ et. al., 2012). Os cursistas são organizados em pequenos grupos de quatro ou cinco membros com habilidades, especialidades, valores, perspectivas e experiências profissionais diferentes. Adotamos o estilo de mentoria por círculo (EDUCASE, $\mathrm{s} / \mathrm{n}$ ) uma vez que procuramos fomentar o diálogo, a comunicação e a discussão entre os membros do grupo. Para melhor compreensão da organização pedagógica do REMAES, na sequência apresentamos a dinâmica de trabalho da equipe de formadores.

\section{Redes que formam e transformam múltiplas redes de aprendizagem}

Ao constituir o grupo de formadores do programa RE-MAES e selecionar os professores-cursistas, seguimos os apontamentos de Abrucio (2016) que defende a aproximação da Universidade (nesse caso do Instituto Federal) com as Redes de Ensino estadual, municipal e particular, e Escolas, formando o "tripé formativo" das instituições responsáveis pela melhoria da educação brasileira.

Assim, selecionamos 20 professores com perfil de formadores não somente em exercício no Instituto Federal, como também atuantes na rede estadual, municipal e particular de ensino de Nova Andradina e região. Já, a equipe de formadores foi constituída por professores de diferentes áreas de atuação e níveis de escolaridade, totalizando 11 profissionais envolvidos diretamente na proposta. A fim de garantir a colaboração de todos, organizamos três círculos de planejamento, denominados: REMAES currículo, RE-MAES planejamento e RE-MAES execução.

Fazem parte do RE-MAES currículo sete professores egressos dos Programas Finlandeses de formação de professores VET Teacher for Future e FiTT Finnish Training the Trainers. Os professores são pertencentes ao quadro efetivo de professores da Educação Básica, Técnica e Tecnológica (EBTT), em exercício nas seguintes instituições e estados: Instituto Federal de Mato Grosso do Sul IFMS (1); Instituto 
Federal de Rondônia IFRO (2); Instituto Federal de Brasília IFB (2); Instituto Federal do Triângulo Mineiro IFTM (1); Instituto Federal do Espírito Santo (1). Cabe aos professores desse círculo a atuação, principalmente, como idealizadores do currículo do RE-MAES e pesquisadores da ação em desenvolvimento.

O RE-MAES planejamento é formado por quatro professores formadores. Nesse círculo são planejadas as ações pedagógicas que conduzirão o desenvolvimento das competências previstas pelo curso. Vale registrar, que dois professores do círculo do RE-MAES currículo integram esse grupo, junto com dois professores formadores do círculo de execução, sendo dois professores do IFMS, um professor do IFB e um professor do IFES.

O RE-MAES execução é a equipe de formadores responsáveis pela implementação do Programa RE-MAES no IFMS, campus Nova Andradina. Fazem parte da equipe de execução três professores do IFMS e um estudante egresso do curso técnico integrado ao Ensino Médio em Informática, atuando como formadores locais e mentores no desenvolvimento cognitivo e socioemocional de cada cursista.

\section{A Ressignificação do FiTT em diálogo com o contexto}

A tentativa de reconstruir os caminhos percorridos pelo outro ao implementar um currículo por competências de Programa de Formação de Professores a fim de multiplicar os saberes construídos, nos faz perceber que somos levados a estabelecer novos caminhos determinados pelas especificidades do contexto de atuação.

A base teórica escolhida e utilizada pelos finlandeses para sustentar o FiTT Finnish Training the Trainers no que concerne ao delineamento do currículo e à abordagem pedagógica se mantêm, no entanto, os pressupostos práticos passam pelo grifo caleidoscópico dos formadores em constante diálogo com a realidade e expectativa dos professores cursistas. É nesse ponto que o currículo do RE-MAES se caracteriza como aberto, participativo e flexível.

Diferentemente do FiTT, o programa de formação continuada de professores brasileiro RE-MAES deixa de ser intensivo a fim de atender professores em exercício, sendo que concomitantemente ao curso objetiva-se que reflitam sobre e na prática de formar professores em escolas públicas e particulares. Ainda, com o intuito de atender o profissional com jornada dupla de trabalho mais um terceiro turno destinado à formação

RPGE - Revista on line de Política e Gestão Educacional, Araraquara, v. 22, n. 2, p. 554-571, maio/ago., 2018. ISSN: 1519-9029. DOI: $10.22633 /$ rpge.v22.n2.maio/ago.2018.11429 
em serviço, o RE-MAES adota ações pedagógicas híbridas, explorando assim os espaços virtuais de aprendizagem.

Quanto às competências desenhadas fez-se pertinente o enfoque na produção de conhecimentos científicos sobre currículo, currículo por competência e abordagem pedagógica. Com isso, o RE-MAES é guiado por dois projetos, um que terá como produto o currículo por competência de um programa de formação continuada de professores que atenda a demanda local e outro, cujo produto é a produção científica da aprendizagem construída a partir de uma problemática que se constitua no contexto de atuação do profissional. Adicionamos tal competência por considerar que o perfil do professor atual demanda a capacidade de "diagnosticar problemas, de refletir e investigar sobre eles, construindo uma teoria adequada (teorias práticas) que orientem a tomada de decisões" (ALONSO, 2007, p. 46).

O público-alvo do RE-MAES também não é o mesmo desenhado no FiTT, são formados pelo RE-MAES professores com perfis de liderança e que, preferencialmente, estejam com a função de formar professores na escola estadual, federal, municipal ou particular.

Optamos por propor uma carga horária para o desenvolvimento das competências que norteiam o currículo. Isso significa que caberá ao cursista construir seu percurso de formação a partir de sua necessidade e disponibilidade, levando em consideração princípios como respeito, responsabilidade, solidariedade, afetividade e honestidade ao estabelecer interação com colegas e mentores.

A adoção de mentoria por círculo é outra característica do RE-MAES que não foi adotada nos caminhos metodológicos do FiTT, todavia alinha-se ao paradigma de formação inicial e continuada de professores finlandeses.

\section{Considerações finais}

Com as demandas no Século XXI novas formas de ensinar e aprender têm sido discutidas, também devido ao advento das novas tecnologias digitais que acabam moldando os relacionamentos entre as pessoas e os instrumentos (LÉVY, 1993). Neste cenário a formação continuada do professor torna-se essencial, de modo que se aproxime da realidade fora dos muros escolares. Os contextos formais, informais e nãoformais se entrelaçam e se expandem, da mesma forma os espaços formativos demandam a ampliação de possibilidades e oportunidades de constantes aprendizagens. 
É nesta perspectiva que esse estudo se insere, visando investigar práticas formativas, criando possibilidades aos professores de formação e transformação da realidade, ao mesmo tempo que nos preocupamos em pesquisar os resultados de tais ações.

Entendemos que as tendências globais de práticas educacionais e de formação de professores precisam ser investigadas em seu contexto cultural. Com esse intuito, o REMAES foi ressignificado, a partir do FiTT - um programa finlandês de formação de professores, customizado para o público-alvo, professores do Ensino Básico, Técnico e Tecnológico - considerando aspectos culturais nacional e regional, além das peculiaridades do trabalho docente diário: distribuição da carga horária semanal, condições de trabalho e o modo de vida que se estabelece com a inserção das tecnologias digitais no dia-a-dia.

Consideramos na ressignificação do RE-MAES aspectos importantes como o da flexibilidade, a autenticidade, a participação e a colaboração na construção do currículo para formação de educadores. Outras características foram adicionadas com o objetivo de promover alternativas que se adequem à rotina do professor; a opção da aprendizagem online é um exemplo. Além disso, organizamos os grupos de mentores de modo que pudéssemos individualizar a formação.

O estudo demonstra o movimento dialético de ação-reflexão-ação entre os sujeitos envolvidos, traduzido no delineamento prático do currículo do RE-MAES. Nas práxis investigativa e colaborativa os formadores constituem-se como transformadores de uma experiência curricular e ao mesmo tempo são transformados pela realidade do contexto educacional que se inserem.

O RE-MAES coloca-se como uma ação formativa extremamente importante e inovadora em um período histórico de incertezas, em que há corte de orçamento em todos os setores no Brasil, incluindo a educação, de reformas curriculares, de novas propostas para a base comum etc. É nesse cenário que, cada vez mais, a formação continuada torna-se imperativa e carente de propostas sustentáveis.

Entendemos que uma segunda fase da pesquisa deve ser desenvolvida, buscando compreender as peculiaridades do processo, desde como se dá o compartilhamento dos saberes construídos na ação e a aproximação dessas com as teorias estudadas, a interação online, a relação nos grupos de mentoria, a aplicação das aprendizagens na prática pedagógica etc.

RPGE - Revista on line de Política e Gestão Educacional, Araraquara, v. 22, n. 2, p. 554-571, maio/ago., 2018. ISSN: 1519-9029. DOI: $10.22633 /$ rpge.v22.n2.maio/ago.2018.11429 


\section{REFERÊNCIAS}

ABRUCIO, F. L. Formação de Professores no Brasil: Diagnóstico, agenda de políticas e estratégias para a mudança. São Paulo: Moderna, 2016.

ALONSO, L. Perfil profissional e projecto de formação. In: LOPES, A. (org.). De uma escola a outra: Temas para pensar a formação inicial de professores. Porto: Edições Afrontamento / CIIE, 2007.

DELORS, J. Educação: um tesouro a descobrir. São Paulo: UNESCO/Edições ASA/Cortez, 1998. Disponível em:

<http://dhnet.org.br/dados/relatorios/a_pdf/r_unesco_educ_tesouro_descobrir.pdf > . Acesso em: 10 dez. 2017.

EDUCAUSE (n.d.). Mentoring Styles. Disponível em:

$<$ http://www.educause.edu/careers/special-topic-programs/mentoring/aboutmentoring/mentoring-styles>. Acesso em: 15 jan. 2018

KOENEN, A.K.; DOCHY, F.; BERGHMANS, I. A phenomenographic analysis of the implementation of competence based education in higher education. Teaching and Teacher Education, v. 50, p. 1-12, 2015.

LÉVY, P. As tecnologias da inteligência: o futuro do pensamento na era da informática. Tradução de Carlos Irineu da Costa. Rio de janeiro: Editora 34, 1993.

MASETTO, M. T. Mediação Pedagógica e o uso da tecnologia. In: MORAN, J.M.; MASETTO, M. T; BEHRENS, M. A. Novas tecnologias e mediação pedagógica. Campinas, SP: Papirus. 2000, p. 133-173.

STRUYVEN, K.; MEYST, M. D. Competence-based teacher education: Illusion or reality? An assessment of the implementation status in Flanders from teachers' and students' points of view. Teaching and Teacher Education, v. 26, n.8, p. 1495-1510, 2010. Disponível em: <https://www.academia.edu/1973445/Competence-

based_teacher_education_Illusion_or_reality_An_assessment_of_the_implementation_s tatus_in_Flanders_from_teachers_and_students_points_of_view>. Acesso em: 10 jan. 2018.

THE EUROPEAN HIGHER EDUCATION AREA. The Bologna Declaration of 19 June 1999: Joint Declaration of the European Ministers of Education. Disponível em: <https://www.eurashe.eu/library/modernising-phe/Bologna_1999_BolognaDeclaration.pdf >. Acesso em já: 10 jan. 2018.

TYNJÄLÄ, P., HEIKKINEN, H. L. T. \& JOKINEN, H. (eds.). Peer-Group Mentoring for Teacher Development. London and New York, Routledge, 2012. 


\section{Como referenciar este artigo}

VIEIRA, Azenaide Abreu Soares; CHEDIAK, Sheylla. Currículo Baseado em Competências na Formação Continuada de Professores da Educação Profissional e Tecnológica: contribuições de programas finlandeses. Revista on line de Política e Gestão Educacional, Araraquara, v. 22, n. 2, p. 554-571, maio/ago., 2018. ISSN: 15199029. DOI: 10.22633/rpge.v22.n2.maio/ago.2018.11429

Submetido em: 28/02/2018

Revisões requeridas: 10/04/2018

Aprovado em: 15/05/2018 